\title{
Construção de fractais usando o software GeoGebra
}

\author{
Teresinha Aparecida Faccio Padilha \\ Mestre, Centro Universitário Univates \\ teresinhafaccio@gmail.com
}

\section{Maria Madalena Dullius \\ Professora, Centro Universitário Univates \\ madalena@univates.br}

\author{
Marli Teresinha Quartieri \\ Professora, Centro Universitário Univates \\ mtquartieri@univates.br
}

\begin{abstract}
Resumo
O relato aborda uma pesquisa que teve por objetivo investigar como a construção de fractais com o software GeoGebra poderia suscitar conhecimentos geométricos e algébricos. Desenvolveu-se uma intervenção pedagógica com alunos da $7^{\mathrm{a}}$ série do Ensino Fundamental e após, aplicou-se um questionário aos discentes envolvidos com o intuito de realizar uma avaliação em relação às atividades exploradas. De acordo com as análises feitas e tendo por base as respostas do questionário, a produção dos alunos e as observações registradas durante o desenvolvimento da intervenção pedagógica ficou evidenciado que: o trabalho contribuiu na obtenção de uma forma motivadora, interativa e viável da abordagem da Geometria Fractal; o software GeoGebra foi importante ferramenta de apoio na construção dos fractais; a Geometria Fractal é uma possibilidade interessante de associar a geometria e a álgebra numa proposta diferenciada de forma a contemplar as duas áreas de conhecimento.
\end{abstract}

Palavras chave: Geometria. Álgebra. Fractais. GeoGebra.

\section{Construction of fractals using the software GeoGebra}

\begin{abstract}
The report discusses a research that aimed to investigate with the software GeoGebra could create geometric and algebraic skills. It was developed an educational intervention with seventh graders of Elementary School and, after, it was applied a questionnaire to students involved in order to accomplish and make an assessment regarding the activities explored. According to the analyzes and based on the questionnaire answers, the production performed by students during the development of educational intervention, it was evident that: the work contributed in achieving a motivating way, interactive and viable approach of Fractal Geometry: the software GeoGebra was an important tool in the construction of fractals; the Fractal Geometry is an interesting possibility of linking geometry and algebra in a different proposal in order to contemplate and reflect the two areas of knowledge.
\end{abstract}

Keywords: Geometry. Algebra. Fractals. GeoGebra. 


\section{Introdução}

A motivação de trabalhar com a geometria surge com a percepção do quão ela permeia e é importante no mundo em que vivemos. Já a opção pela abordagem dos fractais é feita tendo presente a insuficiência da geometria euclidiana na contemplação das diferentes formas da natureza e sua crescente aplicabilidade em diferentes áreas. Contudo, a construção manual de muitos fractais pode ser uma atividade trabalhosa, exigindo tempo e precisão de medidas, processo que pode ser facilitado com a utilização de um recurso computacional.

Desenvolvemos então uma pesquisa cujos procedimentos adotados na coleta e análise de dados traduzem uma visão qualitativa de investigação e encontram-se em harmonia com a definição apresentada por Javaroni, Santos e Borba (2011). Os autores afirmam que a investigação qualitativa é uma forma de se fazer pesquisa na qual o foco e o olhar encontram-se nas relações que têm significado para o pesquisador.

O objetivo geral da pesquisa foi investigar como a construção de fractais com o uso do software GeoGebra pode suscitar a produção de conhecimentos geométricos e algébricos. Os objetivos específicos foram: identificar possíveis conhecimentos geométricos e algébricos utilizados na construção de fractais e investigar as contribuições do software GeoGebra na abordagem de conteúdos de geometria.

\section{Abordagem teórica}

Não são mais tão recentes as discussões acerca do uso do computador e suas implicações no ensino. Rezende (2002) já afirmava que não se trata mais de nos perguntarmos se devemos ou não introduzir as novas tecnologias da informação e da comunicação no processo educativo, mas sim em como utilizá-las. A autora ressalta que a introdução destas por si só no ensino não implica necessariamente mudanças de práticas pedagógicas, pois podemos com elas apenas vestir o velho com roupa nova. Assim, aproveitar as potencialidades do recurso computacional de modo a melhorar o ensino é um desafio.

Cientes das considerações feitas, utilizamos o software GeoGebra ${ }^{1}$ no decorrer do nosso processo investigativo. O software possibilita a exploração de objetos geométricos e algébricos de forma interativa, como o próprio nome sugere GEOmetria+álGEBRA, sendo assim destinado ao ensino de Geometria, Álgebra e Cálculo. Um de seus diferenciais é a opção de se criar uma nova ferramenta que facilita a construção de fractais, evitando o maçante exercício de repetição que o uso do papel e caneta exigiria.

1. O software GeoGebra encontra-se disponível em www.geogebra.org 
O termo geometria fractal foi denominado por Benoit Mandelbrot por volta da década de cinquenta e desde então, sua aplicação é crescente em diferentes áreas. $\mathrm{Na}$ educação tem-se descoberto conexões interessantes entre os fractais e os ramos da Matemática que devido sua complexidade encontram no computador um grande aliado ao mostrar tais ligações com rapidez como afirma Della Nina (2007). A autora explorou os fractais nos movimentos da Torre de Hanói junto a alunos de Ensino Médio e diz que se não tivessem feito uso do computador não teriam tido tempo ou paciência na construção dos gráficos que transformou a sequência de movimentos dos discos da Torre em lindos fractais geométricos em forma de estrelas.

Para fins de nosso estudo optamos pela definição de fractal dada por Barbosa (2005) que se refere aos fractais como entes que constituem uma imagem de si própria em cada uma de suas partes, sendo estas semelhantes e caracterizando assim a propriedade da autossimilaridade.

\section{Intervenção pedagógica}

A intervenção pedagógica foi desenvolvida com uma turma de $7^{\mathrm{a}}$ série $\left(8^{\circ}\right.$ ano) do Ensino Fundamental da E. M. E. F. Otto Gustavo Daniel Brands no município de Venâncio Aires, RS.

Para dar início a intervenção pedagógica a professora-pesquisadora propôs uma atividade que despertasse nos alunos a percepção da insuficiência da Geometria Euclidiana na representação de elementos da natureza. Começou com um questionário que os instigou sobre quais formas geométricas conheciam. Na sequência os alunos foram convidados a observar objetos ou elementos quaisquer da natureza e associar às formas geométricas conhecidas. As dificuldades encontradas foram exploradas, seguindo com um questionamento sobre as formas da natureza poderem ser associadas ou construídas a partir das figuras geométricas euclidianas. Após foram realizados mais alguns questionamentos: Como a natureza sabe construir essas estruturas? Como ela sabe a regra de construção? Na continuidade comentou o surgimento da geometria fractal e a apresentou em forma de slides com imagens, exemplificando, conceituando e mostrando diferentes aplicações.

Foram assim construídos fractais como a Curva de Koch, a Ilha de Koch, o Triângulo de Sierpinski e o Tapete de Sierpinski. A partir de uma pesquisa sobre o Triângulo de Pascal e sua relação com o fractal Triângulo de Sierpinski os alunos investigaram possibilidades de obtenção de uma estrutura fractal após a identificação de diferentes múltiplos no referido triângulo. Isso tudo na interface do software GeoGebra. Também foram construídos fractais sob a forma de cartões e sólidos tridimensionais fazendo uso de diferentes materiais. 
Na sequência detalharemos apenas duas das atividades desenvolvidas juntamente com as análises realizadas.

\section{1) Construção da Curva de Koch com o software GeoGebra}

A Curva de Koch foi construída no GeoGebra com o objetivo de mobilizar conhecimentos acerca da classificação dos triângulos, segmentos de reta, semirretas, paralelismo, circunferência, potenciação e números racionais.

O uso da ferramenta computacional, no caso o software GeoGebra, fez com que o trabalho maçante da repetição do padrão geométrico em questão não acontecesse, cedendo o tempo para o desenvolvimento de habilidades como a capacidade de sintetizar e analisar.

A observação da atividade proposta, após a construção do fractal no GeoGebra e exemplificada pela Figura 1, nos permite constatar que os alunos fizeram uso da potenciação e do número fracionário para representar o número de segmentos e os respectivos comprimentos evidenciando apropriação do conhecimento. Também cabe destacar a utilização da álgebra presente nas generalizações como importantes aprendizagens consolidadas.

Figura 1 - Atividade apresentada pelo aluno A2.

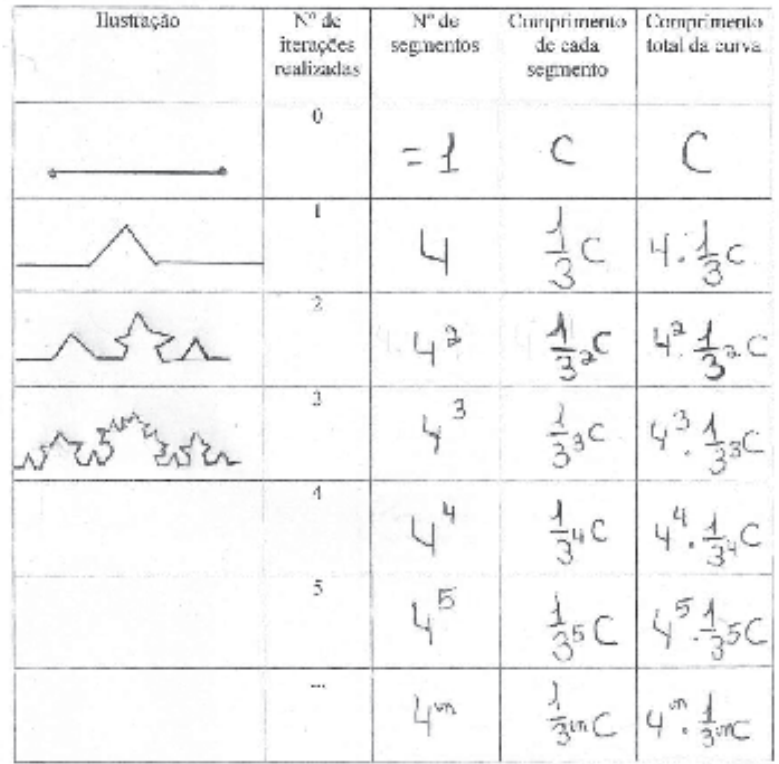

Fonte: Atividade apresentada pelo Aluno A2. 
Ademais, podemos destacar o fato de que foram os alunos que forneceram informações e comandos para que o software realizasse o que desejavam e o que era conveniente para a ocasião, numa espécie de programação. Não foi uma simples combinação de teclas ou ícones para que tudo estivesse pronto. Foi perceptível a mobilização de conceitos e estratégias já presentes na bagagem cultural de cada um, bem como a busca por outros que a atividade exigia.

Assim, podemos perceber a realização do ciclo descrever - executar - refletir e depurar, descrito por Valente (1997) nesta interação com o computador através da programação que não acontece simplesmente colocando o aluno na frente da máquina sem uma intervenção qualitativa do docente.

\section{2) Construção do Triângulo de Sierpinski com o software GeoGebra}

A construção do Triângulo de Sierpinski no GeoGebra e posterior exploração foi proposta com a intenção de que os alunos identificassem a regra utilizada na construção do fractal. Também pretendíamos a consolidação de conceitos sobre perímetro, área, classificação de triângulos, porcentagem, bem como a elaboração de generalizações.

A construção, como observado na sequência de imagens mostradas na Figura 2, partiu de um triângulo equilátero feito com uso do ícone "Polígono regular" e um novo triângulo tendo por base o ponto médio de cada lado do triângulo inicial marcado com ferramenta do software. Foi então criada uma ferramenta para repetir o processo a cada nova iteração através do ícone "Ferramenta" - "Criar nova Ferramenta".

Figura 2 - Passos da construção do Triângulo de Sierpinski.
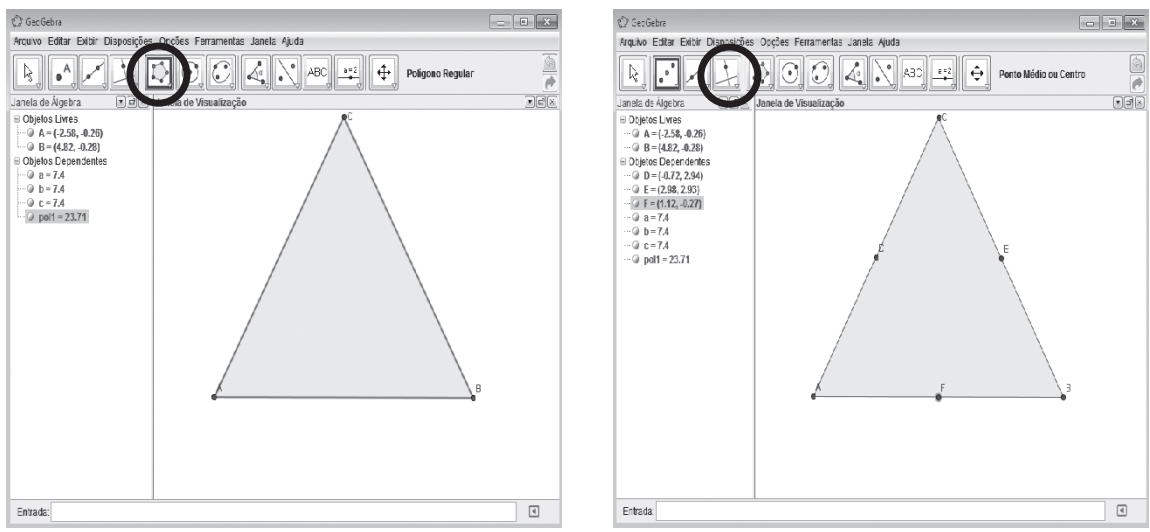

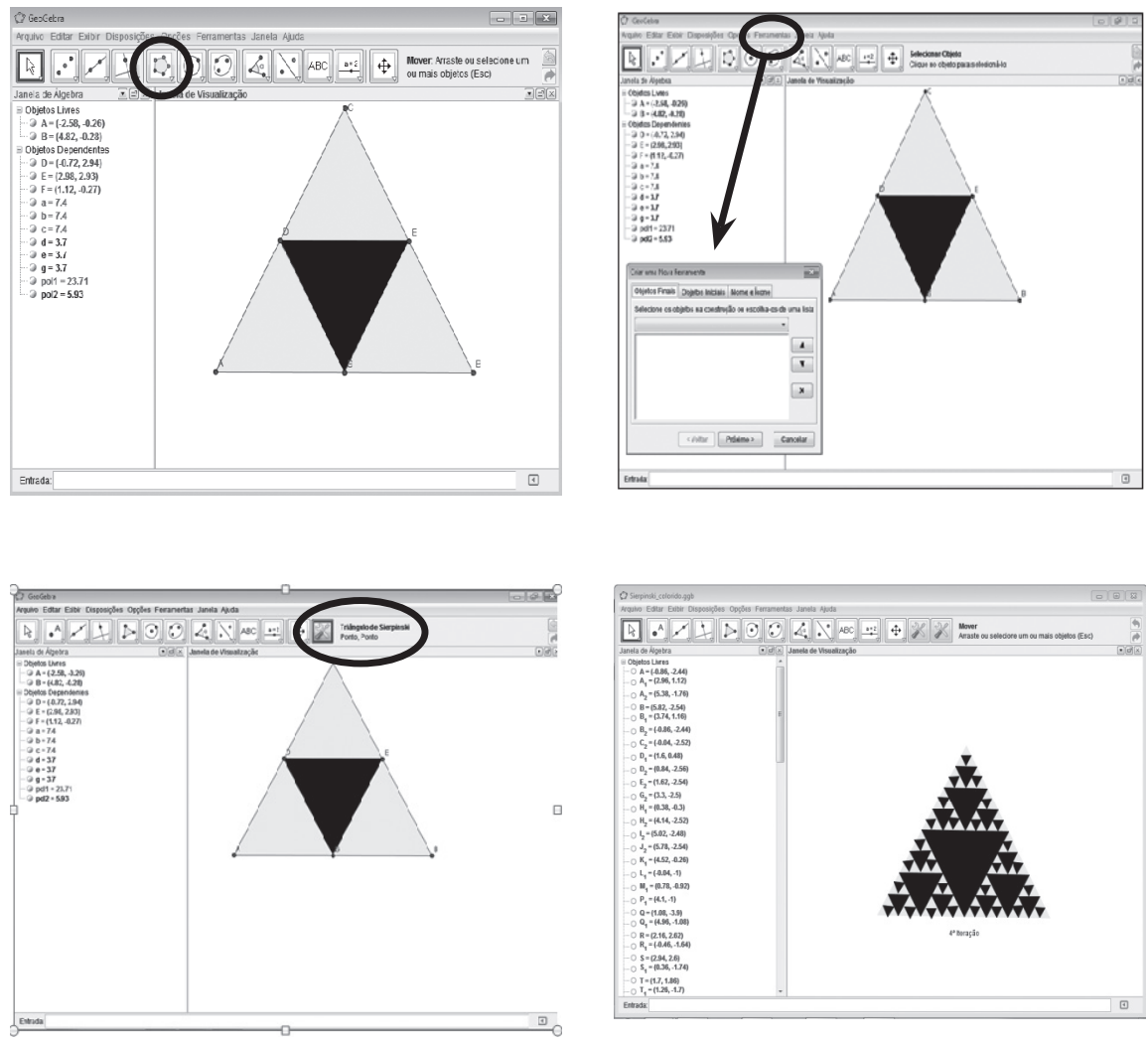

Fonte: Interface do GeoGebra.

Observar as construções fractais realizadas e nelas conseguir identificar padrões geométricos e aritméticos presentes e ainda mais, fazer uso de letras como forma de representar suas generalizações contribuiu para que o uso da álgebra não ocorresse de forma "mecanizada".

\section{Avaliação da intervenção pedagógica na visão dos alunos}

Apresentamos os resultados obtidos por meio de um questionário que foi aplicado no último encontro aos alunos participantes da prática pedagógica.

Ao destacarem as contribuições do software GeoGebra no processo de aprendizagem foi salientado por todos a precisão das medidas e a rapidez na realização das iterações fractais. A interação entre os colegas e os momentos de troca foram salientados. 
Quanto às dificuldades encontradas no que se refere ao uso do software foram citadas a pouca exatidão na localização que tinham quando desejavam marcar um ponto em determinado lugar na tela devido a defeitos funcionais dos mouses em uso. O pouco discernimento tido no momento da escolha da ferramenta adequada para atender ao que desejavam também foi explicitado como empecilho. Este, portanto, é um aspecto que consideramos positivo, pois estabelecer critérios de escolha durante as construções é um objetivo que almejamos, visto que a dificuldade não consistia no pouco esclarecimento da função desempenhada por cada ícone, mas no planejamento e execução das etapas da construção do fractal.

A análise das respostas obtidas por intermédio do questionário nos permite concluir que a temática fractal foi propulsora do desenvolvimento de conteúdos matemáticos de forma diferenciada e prazerosa. Além disso, a associação da álgebra e da geometria fractal foi de grande valia na consolidação das aprendizagens.

\section{Considerações Finais}

O uso de recursos computacionais trouxe significativas contribuições ao desenvolvimento de nossa proposta. Com uma interface de fácil entendimento o software GeoGebra ofereceu condições para manipulação dos diferentes componentes das figuras construídas permitindo a exploração e realização de conjecturas de forma a embasar a construção de conceitos geométricos e algébricos. A possibilidade de visualização dos diferentes níveis de cada fractal mesmo após sua conclusão proporcionando uma espécie de feedback foi outra vantagem da utilização deste recurso.

A precisão das medidas ao passo que as iterações fractais iam aumentando foi outra contribuição obtida com o software GeoGebra. Manualmente com uso de recursos convencionais como régua e compasso fazer medições em intervalos de espaços muito pequenos é uma tarefa que requer muita habilidade. Assim, o ambiente computacional proporcionou exatidão aos traçados e otimizou o tempo gasto que desprenderíamos com o fazer manual dos fractais.

Contemplar os aspectos harmoniosos e observar as regularidades nas próprias irregularidades de cada fragmento fractal permitiu a percepção do condicionamento desses aos aspectos algébricos e geométricos favorecendo a exploração de tais conhecimentos. Percebemos a evolução dos alunos na apropriação da simbologia algébrica através de registros e verbalizações fortalecidos pelo vínculo da álgebra a questões reais e não a meros exercícios mecânicos.

A abordagem a geometria fractal além de ter proporcionado descobertas fascinantes e ampliado o campo de visão geométrico favoreceu o desenvolvimento de conteúdos típicos da geometria euclidiana como classificação de triângulos, qua- 
driláteros, retas, semirretas, ponto, paralelismo, simetria, entre outros, reforçando essa fusão. Quanto à álgebra ela esteve presentes nas generalizações realizadas.

Concordamos com Dullius et al (2011) ao afirmarem que não há mais como negar que o recurso computacional é uma poderosa ferramenta para romper o formalismo e transformar o ato de "ensinar" numa inter-relação produtiva e revolucionária, na qual a prática educativa contribua para a melhoria da qualidade de vida da sociedade e da educação.

\section{Referências}

BARBOSA. R. M. Descobrindo a geometria fractal - para a sala de aula. 2. ed. Belo Horizonte: Autêntica, 2005.

DELLA NINA, C. T. Brincando com a Torre de Hanói e descobrindo fractais: Uma sugestão de atividade para o Ensino Médio. Boletim GEPEM, n. 50, p. 75-85, 2007.

DULliUS; M. M.; QUARTIERI, M. T.; BERGMANN, A. B.; PADILHA, T. A. F. Formação de professores: elaboração e análise de atividades para explorar trigonometria usando software. Tecné, Episteme y Didaxis: Revista de la Facultad de Ciencias y Tecnologia - Universidad Pedagógica Nacional. Bogatá, 2011.

JAVARONI, S. L.; SANTOS, S. C.; BORBA, M. C. Tecnologias digitais na produção e análise de dados qualitativos. Educação Matemática Pesquisa, v. 13, n.1, p. 197-218, 2011.

REZENDE, F. As novas tecnologias na prática pedagógicas sob a perspectiva construtivista. Ensaio-Pesquisa em Educação em Ciências, v. 2, n. 1, 2002.

VALENTE, J. A. O uso inteligente do computador na educação. Revista Pátio, n. $1,1997$.

Submetido em janeiro de 2013. Aprovado em março de 2013. 